\title{
Distinguishing seawater from geologic brine in saline coastal groundwater using radium-226; an example from the Sabkha of the UAE
}

\author{
Thomas F. Kraemer ${ }^{\text {a,c,*}}$, Warren W. Wood ${ }^{\mathrm{b}}$, Ward E. Sanford ${ }^{\mathrm{c}}$ \\ a U.S. Geological Survey, Woods Hole Coastal and Marine Science Center, 384 Woods Hole Rd., Woods Hole, MA 02543, United States \\ b Department of Geological Sciences, Michigan State University, East Lansing, MI 48824, United States \\ c U.S. Geological Survey, 12201 Sunrise Valley Dr., Reston, VA 20192, United States
}

\section{A R T I C L E I N F O}

\section{Article history:}

Received 1 May 2013

Received in revised form 24 January 2014

Accepted 27 January 2014

Available online 6 February 2014

Editor: J. Fein

\section{Keywords:}

Sabkhat

Radium-226

Geologic brine

Seawater

\begin{abstract}
A B S T R A C T
Sabkhat (Salt flats) are common geographic features of low-lying marine coastal areas that develop under hyperarid climatic conditions. They are characterized by the presence of highly concentrated saline solutions and evaporitic minerals, and have been cited in the geologic literature as present-day representations of hyper-arid regional paleohydrogeology, paleoclimatology, coastal processes, and sedimentation in the geologic record. It is therefore important that a correct understanding of the origin and development of these features be achieved. Knowledge of the source of solutes is an important first step in understanding these features. Historically, two theories have been advanced as to the main source of solutes in sabkha brines: an early concept entailing seawater as the obvious source, and a more recent and dynamic theory involving ascending geologic brine forced upward into the base of the sabkha by a regional hydraulic gradient in the underlying formations. Ra-226 could uniquely distinguish between these sources under certain circumstances, as it is typically present at elevated activity of hundreds to thousands of $\mathrm{Bq} / \mathrm{m}^{3}$ (Becquerels per cubic meter) in subsurface formation brines; at exceedingly low activities in open ocean and coastal water; and not significantly supplied to water from recently formed marine sedimentary framework material. The coastal marine sabkha of the Emirate of Abu Dhabi was used to test this hypothesis. The distribution of Ra-226 in 70 samples of sabkha brine (mean: $700 \mathrm{~Bq} / \mathrm{m}^{3}$ ), $7 \mathrm{sam}$ ples of underlying deeper formation brine (mean: $\left.3416 \mathrm{~Bq} / \mathrm{m}^{3}\right)$, the estimated value of seawater $\left(<16 \mathrm{~Bq} / \mathrm{m}^{3}\right.$ ) and an estimate of supply from sabkha sedimentary framework grains $\left(<\sim 6 \mathrm{~Bq} / \mathrm{m}^{3}\right)$ provide the first direct evidence that ascending geologic brine contributes significantly to the solutes of this sabkha system.
\end{abstract}

Published by Elsevier B.V.

\section{Introduction}

Sabkhat (salt flats) are extensive geographic features in many arid and hyper-arid coastal environments of the world and are typically associated with highly concentrated brines occurring in the shallow surficial aquifers beneath the surface. As a result, contemporary sabkha environments have become geological analogs for evaporitic environments in the sedimentary record and therefore it is important to identify and correctly understand the processes responsible for accumulation of solutes in these systems.

Early models of sabkha brine formation assumed that the solutes were concentrated by evaporation of seawater (Kinsman, 1969; Butler, 1969; Patterson and Kinsman, 1977, 1981, 1982) or seawater and shallow groundwater (Hsü and Siegenthaler, 1969; Hsü and Schneider, 1973; McKenzie et al., 1980; Müller et al., 1990).

Later, a fundamentally different model was presented whereby the majority of the water making up these brines was supplied by local rainfall, but solutes originated to a large extent from upward migration of

\footnotetext{
* Corresponding author at: U.S. Geological Survey, Woods Hole Coastal and Marine Science Center, 384 Woods Hole Rd., Woods Hole, MA 02543, United States.

E-mail address: tkraemer@usgs.gov (T.F. Kraemer).
}

geologic brine from deeper formations, with seawater contributing only initially and in a minor way to the composition (Sanford and Wood, 2001; Wood and Sanford, 2002; Wood et al., 2002; Wood et al., 2005; Wood and Sanford, 2007; van Dam et al., 2009).

This ascending brine model ( $\mathrm{BBM}$ ) overcame difficulties inherent in sea water-based models, and was in agreement with solute mass balance, water isotope data, solute ratios and positive hydraulic head in the underlying formations. However, clear direct evidence that the model functioned as described, and is currently active, was lacking. Here we use the presence of Ra-226 to provide such primary evidence based on 1) its elevated activity of several hundred to thousands of $\mathrm{Bq} / \mathrm{m}^{3}$ (Becquerels per cubic meter) in subsurface brines (Kraemer and Reid, 1984; Vengosh et al., 2009), 2) near absence in open ocean and coastal seawater $\left(<16 \mathrm{~Bq} / \mathrm{m}^{3}\right.$, Okubo et al., 1979; Moore et al., 1985; Liu et al., 2010; Su et al., 2010; Ohta et al., 2011; Charette et al., 2013), and 3) lack of supply in significant amounts (as compared to formation brines) by sedimentary grains $\left(<\sim 6 \mathrm{~Bq} / \mathrm{m}^{3}\right)$.

The presence of radium in significant amounts (greater than a few hundred $\mathrm{Bq} / \mathrm{m}^{3}$ ) in the sabkha brine would therefore be strong evidence for the ultimate source of solutes being from geologic brines, whose accumulation in the sabkha brine, additionally, would have to be recent owing to the geologically short half-life of Ra-226 ( $\left.\mathrm{t}_{1 / 2}=1601 \mathrm{y}\right)$. 


\section{Site description}

Our study area is in the coastal region of the Arab Gulf, southwest of Abu Dhabi City in the United Arab Emirates, the classic site where most studies relating to development of sabkha-hosted hyper-saline brines has taken place. The area (Fig. 1) is a flat, low-lying region approximately $300 \mathrm{~km}$ long by $10 \mathrm{~km}$ wide. The surficial formation (Abu Dhabi formation, Wood et al., 2002) upon which the sabkha has developed has been inferred by sedimentalogical and ${ }^{14} \mathrm{C}$ methods at $7000 \mathrm{y}$ or older (Evans, 1995) and by the optically stimulated luminescence method at $8000 \pm 800$ y (Wood et al., 2002), and overlies local cemented Pleistocene age dunes and more regional carbonate deposits of the Middle to Upper Miocene age Gachsaran Fm. (Peebles, 1999).

The wedge-shaped sabkha formation averages $10 \mathrm{~m}$ in thickness (thickest toward the Gulf) and is composed of un-cemented, reworked sand dune deposits of uniform grain size ( $98 \%$ of its mass is between 0.16 and $0.22 \mathrm{~mm}$ ) exhibiting a porosity of approximately 0.38 $(+/-5 \%)$, spatially uniform hydraulic conductivity of approximately $1 \mathrm{~m} / \mathrm{d}(+/-25 \%)$, low hydraulic gradient (0.00014) and seepage velocity of approximately $0.15 \mathrm{~m} / \mathrm{y}$. Annual rainfall, associated with Shamal (north) winds in January through March, averages $60 \mathrm{~mm}$ over the study area. Annual potential evaporation exceeds $3800 \mathrm{~mm}$ (all values from the work of Wood and others, see references cited).

Authigenic mineral precipitation is common and largely limited to the surface and capillary zone below the sabkha surface as water is drawn upward in response to intensive evaporation and regional hydraulic head. Retrograde soluble calcite, dolomite, gypsum, and anhydrite precipitate within the capillary zone, while halite, carnallite, sylvite, and niter precipitate on the sabkha surface.

\section{Methods}

Three different drilling techniques were used in installing the wells and piezometers from which the samples were taken. The shallow RP-series ("R" designations on Fig. 1) piezometer nests were drilled using mud-rotary equipment in a profile perpendicular to the Gulf shoreline approximately $60 \mathrm{~km}$ west of Abu Dhabi City. All piezometer nests, except those at site RP-5, are completed at various depths in the Abu Dhabi formation. Five-centimeter diameter PVC pipe, slotted by a hacksaw on the bottom $0.5 \mathrm{~m}$ and fitted with end cap, identification collar, and cap, was installed into the holes immediately after drilling. Water samples from the RP piezometers were collected by peristaltic pump. Pump tubing was rinsed both inside and out in distilled water prior to sampling, and several liters of brine were pumped to waste before installing an in-line filter for sample collection. Three well volumes were discharged before sampling all wells.

The deep GWP-series of wells ("G" designation on Fig. 1) were drilled parallel to the coast using reverse air rotary equipment and penetrated into the underlying bedrock of Miocene age. These wells were finished with approximately $40 \mathrm{~m}$ of steel surface casing, with open hole for the remainder of their total depth. All of the GWP wells flowed

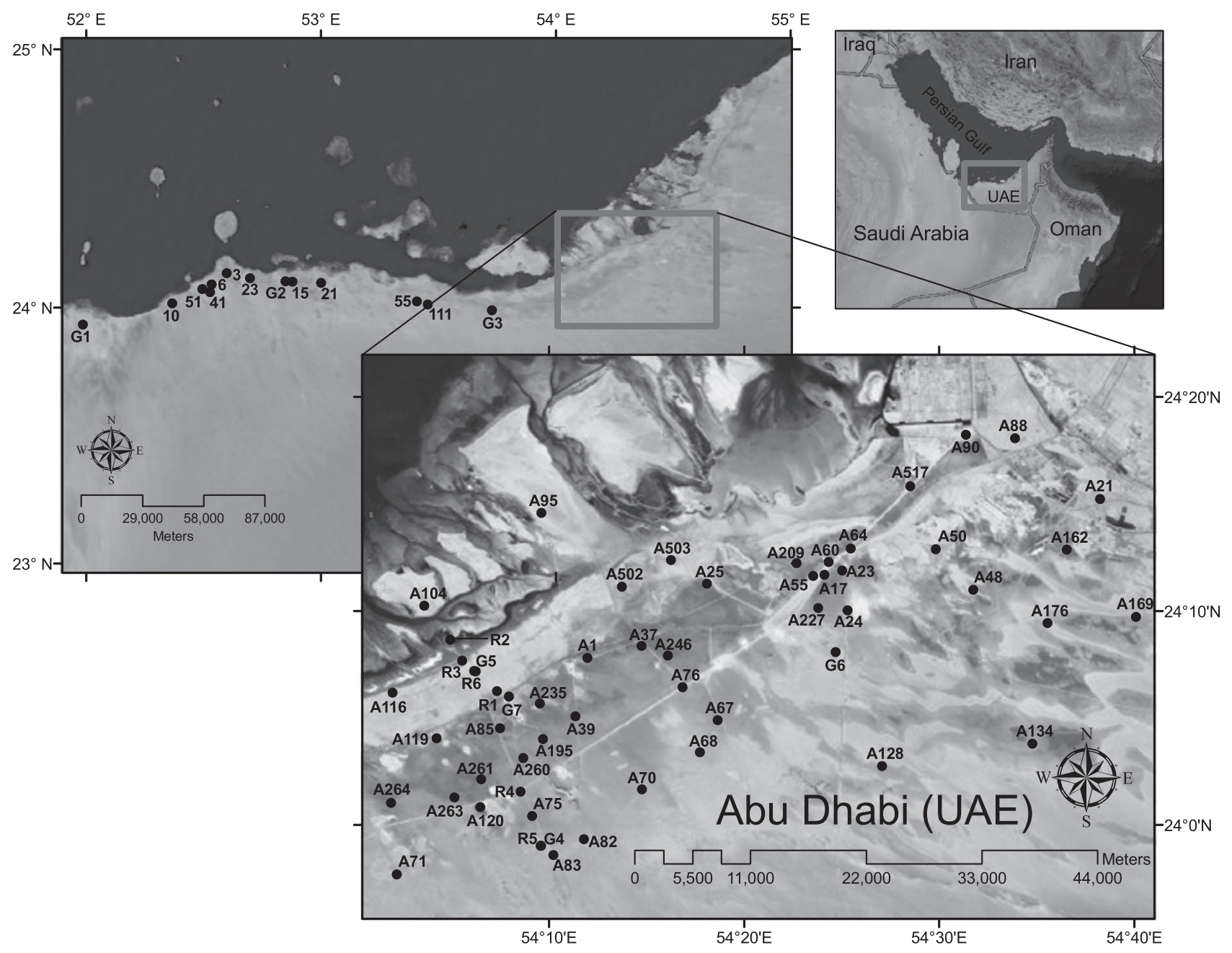

Fig. 1. Location map of study area. Sample designations are described in the text and Table 1. Abu Dhabi City is located just to the north of the expanded box. 
Table 1

Location and Ra-226 activity of samples analyzed.

\begin{tabular}{|c|c|c|c|c|}
\hline \multirow[t]{2}{*}{ Field identification } & \multirow{2}{*}{$\frac{\text { Latitude }}{\mathrm{N}}$} & \multirow{2}{*}{$\frac{\text { Longitude }}{\mathrm{E}}$} & \multirow[t]{2}{*}{ Map } & \multirow{2}{*}{$\frac{{ }^{226} \mathrm{Ra}}{\mathrm{Bq} / \mathrm{m}^{3}}$} \\
\hline & & & & \\
\hline \multicolumn{5}{|l|}{ Sabkha } \\
\hline ABU 001 & 24.1303 & 54.1992 & $\mathrm{~A} 1$ & 338 \\
\hline ABU 017 & 24.1943 & 54.3923 & A17 & 1333 \\
\hline ABU 021 & 24.2543 & 54.6372 & A21 & 302 \\
\hline ABU 023 & 24.1985 & 54.4170 & A23 & 3750 \\
\hline ABU 024 & 24.1673 & 54.4217 & A24 & 7050 \\
\hline ABU 025 & 24.1881 & 54.3012 & A25 & 117 \\
\hline ABU 037 & 24.1396 & 54.2455 & A37 & 352 \\
\hline ABU 039 & 24.0848 & 54.1890 & A39 & 680 \\
\hline ABU 048 & 24.1834 & 54.5291 & A48 & 2217 \\
\hline ABU 050 & 24.2149 & 54.4967 & A50 & 2637 \\
\hline ABU 055 & 24.2049 & 54.4054 & A55 & 537 \\
\hline ABU 060 & 24.1953 & 54.4018 & A60 & 1017 \\
\hline ABU 064 & 24.2156 & 54.4243 & A64 & 540 \\
\hline ABU 067 & 24.0819 & 54.3107 & A67 & 457 \\
\hline ABU 068 & 24.0569 & 54.2953 & A68 & 193 \\
\hline ABU 070 & 24.0278 & 54.2458 & A70 & 325 \\
\hline ABU 071 & 23.9615 & 54.0365 & A71 & 168 \\
\hline ABU 075 & 24.0071 & 54.1520 & A75 & 525 \\
\hline ABU 076 & 24.1075 & 54.2805 & A76 & 400 \\
\hline ABU 082 & 23.9889 & 54.1965 & A82 & 468 \\
\hline ABU 083 & 23.9766 & 54.1703 & A83 & 235 \\
\hline ABU 085 & 24.0755 & 54.1246 & A85 & 322 \\
\hline ABU 088 & 24.3015 & 54.5646 & A88 & 230 \\
\hline ABU 090 & 24.3042 & 54.5227 & A90 & 307 \\
\hline ABU 095 & 24.2433 & 54.1601 & A95 & 475 \\
\hline ABU 104 & 24.1709 & 54.0601 & A104 & 118 \\
\hline ABU 116 & 24.1031 & 54.0330 & A116 & 257 \\
\hline ABU 119 & 24.0676 & 54.0705 & A119 & 692 \\
\hline ABU 120 & 24.0138 & 54.1079 & A120 & 937 \\
\hline ABU 128 & 24.0460 & 54.4511 & A128 & 202 \\
\hline ABU 134 & 24.0633 & 54.5793 & A134 & 42 \\
\hline ABU 162 & 24.2146 & 54.6088 & A162 & 178 \\
\hline ABU 169 & 24.1624 & 54.6679 & A169 & 383 \\
\hline ABU 176 & 24.1574 & 54.5924 & A176 & 2033 \\
\hline ABU 195 & 24.0670 & 54.1613 & A195 & 2033 \\
\hline ABU 209 & 24.2041 & 54.3780 & A209 & 277 \\
\hline ABU 227 & 24.1693 & 54.3966 & A227 & 1268 \\
\hline ABU 235 & 24.0947 & 54.1585 & A235 & 278 \\
\hline ABU 246 & 24.1322 & 54.2681 & A246 & 937 \\
\hline ABU 260 & 24.0521 & 54.1445 & A260 & 650 \\
\hline ABU 261 & 24.0356 & 54.1085 & A261 & 783 \\
\hline ABU 263 & 24.0215 & 54.0856 & A263 & 1043 \\
\hline ABU 264 & 24.0172 & 54.0315 & A264 & 1200 \\
\hline ABU 502 & 24.1858 & 54.2286 & A502 & 533 \\
\hline ABU 503 & 24.2067 & 54.2708 & A503 & 1083 \\
\hline ABU 517 & 24.2641 & 54.4752 & A517 & 1210 \\
\hline RUW 003 & 24.1323 & 52.5980 & 3 & 180 \\
\hline RUW 006 & 24.0897 & 52.5337 & 6 & 103 \\
\hline RUW 010 & 24.0163 & 52.3666 & 10 & 863 \\
\hline RUW 015 & 24.1003 & 52.8785 & 15 & 540 \\
\hline RUW 021 & 24.0958 & 53.0003 & 21 & 2497 \\
\hline RUW 023 & 24.1129 & 52.6971 & 23 & 372 \\
\hline RUW 041 & 24.0599 & 52.5271 & 41 & 58 \\
\hline RUW 051 & 24.0713 & 52.4941 & 51 & 53 \\
\hline TAR 055 & 24.0233 & 53.4090 & 55 & 28 \\
\hline TAR 111 & 24.0112 & 53.4550 & 111 & 12 \\
\hline RP $1-2.5$ & 24.1043 & 54.1219 & $\mathrm{R} 1$ & 152 \\
\hline RP $1-10.0$ & 24.1041 & 54.1219 & & 355 \\
\hline RP 1-36.0 & 24.1043 & 54.1220 & & 330 \\
\hline RP 2-4.5 & 24.1444 & 54.0820 & & 33 \\
\hline RP 2-12.0 & 24.1445 & 54.0820 & $\mathrm{R} 2$ & 15 \\
\hline RP 2-21.0 & 24.1445 & 54.0821 & & 28 \\
\hline RP 3-3.0 & 24.1281 & 54.0922 & R3 & 10 \\
\hline RP 3-10.0 & 24.1281 & 54.0922 & & 23 \\
\hline RP 4-3.0 & 24.0260 & 54.1421 & R4 & 390 \\
\hline RP 5-16 & 23.9839 & 54.1593 & R5 & 543 \\
\hline RP 5-35 & 23.9840 & 54.1593 & & 533 \\
\hline RP 6-10.0 & 24.1198 & 54.1040 & R6 & 313 \\
\hline RP 6-16.0 & 24.1199 & 54.1036 & & 428 \\
\hline RP 6-35.0 & 24.1198 & 54.1040 & & 617 \\
\hline \multicolumn{5}{|l|}{ Miocene bedrock } \\
\hline GWP 289 (119 m) & 23.9891 & 53.7282 & G3 & 745 \\
\hline
\end{tabular}

Table 1 (continued)

\begin{tabular}{|c|c|c|c|c|}
\hline \multirow[t]{2}{*}{ Field identification } & \multirow{2}{*}{$\frac{\text { Latitude }}{\mathrm{N}}$} & \multirow{2}{*}{$\frac{\text { Longitude }}{\mathrm{E}}$} & \multirow[t]{2}{*}{ Map } & \multirow{2}{*}{$\frac{{ }^{226} \mathrm{Ra}}{\mathrm{Bq} / \mathrm{m}^{3}}$} \\
\hline & & & & \\
\hline GWP 290 (88 m) & 23.9839 & 54.1596 & G4 & 910 \\
\hline GWP $288(89 \mathrm{~m})$ & 24.1010 & 52.8476 & G2 & 2333 \\
\hline GWP 306A (137 m) & 24.1003 & 54.1323 & G7 & 3662 \\
\hline GWP $292(119 \mathrm{~m})$ & 24.1347 & 54.4112 & G6 & 4000 \\
\hline GWP 291 (142 m) & 24.1201 & 54.1025 & G5 & 4560 \\
\hline GWP 287A (121 m) & 23.9333 & 51.9859 & G1 & 7688 \\
\hline
\end{tabular}

$\mathrm{Bq} / \mathrm{m}^{3}$ (Becquerels per cubic meter).

$\mathrm{m}$ (meters below land surface).

Map: location in Fig. 1.

and were fitted with a watertight cap, small diameter-sampling pipe, shut-off valve, and pressure gage.

Shallow piezometers (designated "ABU", "TAR", and "RUW" in Table 1 and as alpha-numerics in Fig. 1) were drilled to a depth of between 1 and $2 \mathrm{~m}$ below the water table using a portable, auger-type drill. Five-centimeter diameter PVC pipe, slotted by a hacksaw on the bottom $0.5 \mathrm{~m}$ and equipped with a wooden-drive point, identification collar, and cap, was installed into the holes immediately after drilling.

Chemical analyses of the brines were performed using techniques and methods as reported by Wood et al., 2002. Results of some of the chemical analyses have been reported previously in the publications referenced above describing the ascending brine model (the RP series samples).

Radium analyses were carried out on clear or filtered samples (generally $100 \mathrm{ml}$ or less for shallow sabkha samples, up to $1000 \mathrm{ml}$ for GWP and some RP samples) by adding $6 \mathrm{ml}$ of saturated $\mathrm{Ba}\left(\mathrm{NO}_{3}\right)_{2}$ solution. Normally there was enough natural sulfate present in the sample to precipitate sufficient $\mathrm{Ba}(\mathrm{Ra}) \mathrm{SO}_{4}$ for analysis. However, in a majority of cases $\mathrm{H}_{2} \mathrm{SO}_{4}$ was added to ensure conditions for complete precipitation of barite. The precipitate was collected, washed, dried and placed in a polyethylene vial for counting in a $25 \%$ relative efficiency, well-type HPGe detector. Aliquots of NBS 4539 radium standard were processed in the same manner as the samples to calibrate the efficiency of the processing and counting procedures.

To determine uranium concentration an aliquot of sample was diluted several-hundred fold with $0.1 \mathrm{~N} \mathrm{HCl}$ and analyzed by using the EPA method 200.8 (EPA, 1994) on an Elan 9000 ICP/MS. After uranium concentrations were determined, a suitable volume of sample was processed for U-234/U-238 activity ratio according to the method of Kraemer et al. (2002), using an Elan 9000 ICP/MS with ultrasonic nebulizer.

\section{Results}

77 samples, collected from the entire length of the sabkha, were analyzed for Ra-226 (Table 1) and many also for major ions (Table 2, most from previously unpublished sources). The most intensive sampling was done south of the city of Abu Dhabi, where the sabkha has its maximum width (Fig. 1), and in the area where most of the previous work published in the literature has taken place.

Total dissolved solids of the brines were in general very high, mostly above $200,000 \mathrm{mg} / \mathrm{l}$, similar to results found by others working in the region (Butler, 1969; Patterson and Kinsman, 1981; Kinsman, 1969; McKenzie et al., 1980) and consist of sodium/chloride brines with high concentrations of calcium and magnesium and a $\mathrm{Mg} / \mathrm{Ca}$ ratio (on a mass basis) over a range from 0.5 to 2 , but which in some cases approach 10 (e. g. RP3-3.0), presumably representing areas where gypsum or anhydrite precipitation is occurring. Sulfate is common at nearly all sabkha sites, as well, although in many instances is less concentrated than other, more conservative, ions suggesting removal by sulfate mineral precipitation during the brine formation process. Sulfide was not 
Table 2

Chemical and uranium isotopic composition of some Abu Dhabi sabkha samples.

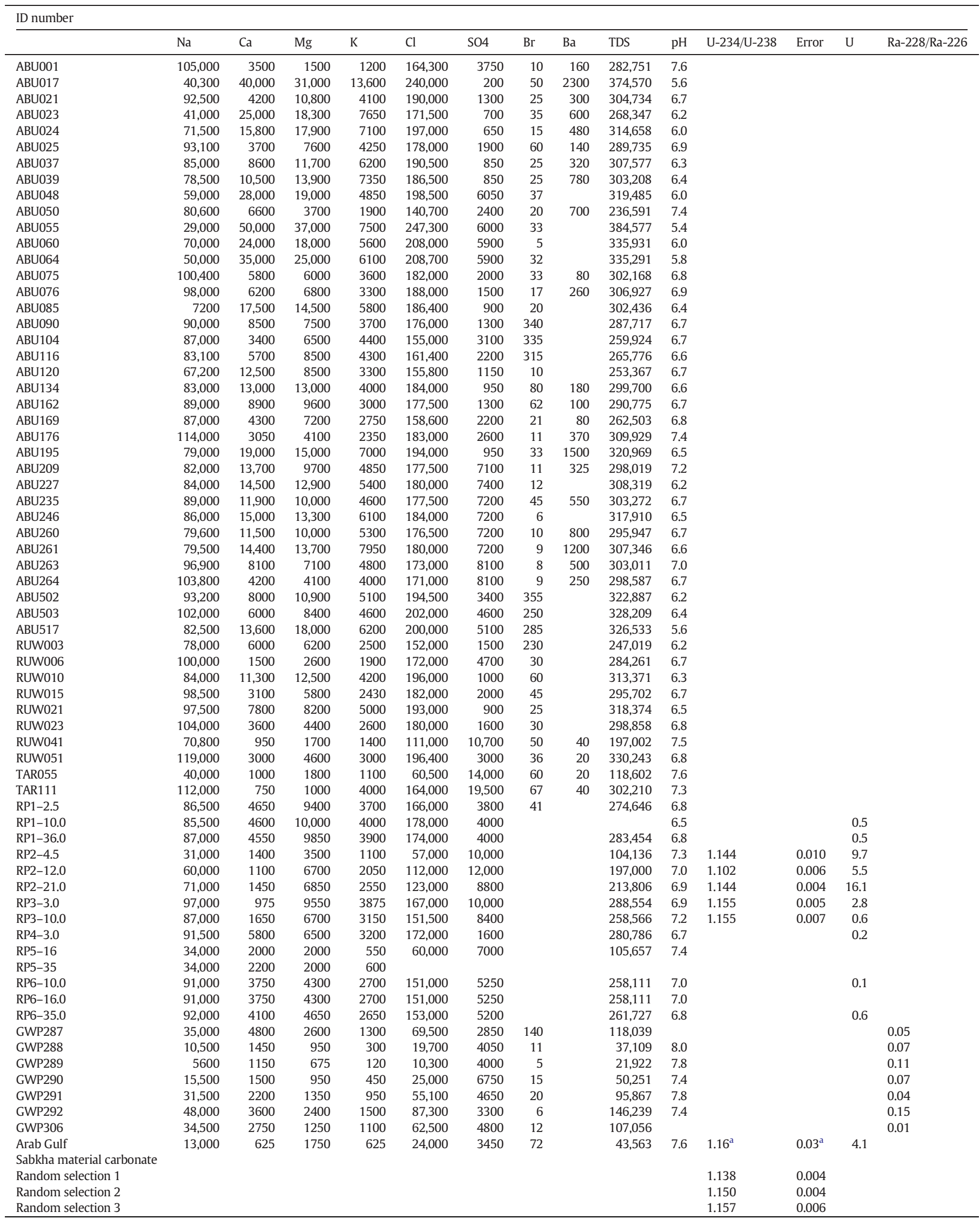


analyzed in any of these samples, but no $\mathrm{H}_{2} \mathrm{~S}$ odor or black precipitate was noticed during the preparation of samples in the field or laboratory.

Varying Ra-226 activity is found in the brine along the extent of the sabkha, including several occurrences greater than $1000 \mathrm{~Bq} / \mathrm{m}^{3}$. A two dimensional picture of greater areal resolution is possible in the area just to the south of the city (Fig. 2), where values reach as high as $7050 \mathrm{~Bq} / \mathrm{m}^{3}$. The lowest-radium areas occur along irregular seaward and landward edges of the sabkha.

Owing to the nature of the gamma spectroscopic method used in this study, Ra-228 as well as Ra-226 can be quantified from the same spectrum, if it is present in sufficient activity. The nature of the sabkha samples is such, however, that due to the generally small sample size available, the activity of Ra-228 present in the sabkha sample aliquots is unquantifiable or undetectable. The GWP-series sample analyses were of sufficient quality that it can be determined that the Ra-228/Ra-226 activity ratio of all samples is less than or equal to 0.15 .

\section{Discussion of sources of radium}

\section{A. Seawater}

The Ra-226 in the sabkha brines could originate from a number of different sources, many of which are difficult to quantify due to a lack of knowledge of the detailed compositions of these possible sources. It is important, however, to reasonably estimate or evaluate their potential magnitudes.

The first possibility to be considered is whether seawater could be a viable source of the Ra-226 by itself. Studies of radium in seawater clearly demonstrate that Ra-226 occurs in quantities less than 1 or $2 \mathrm{~Bq} / \mathrm{m}^{3}$, even in coastal regions receiving riverine supplies of water and sediment (Moore, 1976; Okubo et al., 1979; Moore, 1981; Moore et al., 1985; Liu et al., 2010; Su et al., 2010; Ohta et al., 2011). The coastal Arab Gulf itself has been found to contain low values of Ra-226 of no higher than $5 \mathrm{~Bq} / \mathrm{m}^{3}$ (Fadlelmawla et al., 2013). One sample of Arab Gulf seawater taken from a beach area during our study, in the approximate mid-point of the sabkha study area length, although of small volume, was found to contain no activity of Ra-226 above blank amounts, and is therefore conservatively interpreted to contain Ra-226 activity less than $30 \mathrm{~Bq} / \mathrm{m}^{3}$. It is therefore unlikely that seawater could be the major source of the highest radium activities found in the sabkha brines. It could, however account for the Ra-226 found around the RP2 (within $10 \mathrm{~m}$ of high tide) and RP3 (also close to the coast) piezometer nests. Here, the Ra-226 values range between 10 and $33 \mathrm{~Bq} / \mathrm{m}^{3}$. Assuming a 7-fold evaporation based on the dissolved chloride ratio between RP3-3 $(167,000)$ and Arab Gulf water $(24,000 \mathrm{mg} / \mathrm{l})$, the Ra-226 activity of seawater would be between 1.4 and $4.7 \mathrm{~Bq} / \mathrm{l}$, consistent with reported values. In like manner, the lowest values found in sabkha brine along the rest of the sabkha could also be attributed to a seawater source.

B. Matrix

The other source of radium that needs to be considered is the sedimentary framework material itself. All Earth surface material contains some $U$ and $T h$, and therefore, radium that could potentially be supplied to the brine, either by chemical or physical (alpharecoil) processes.

Two chemical processes could contribute radium to the brine. One is dissolution of mineral grains containing radium, the other is desorption of radium from surface locations on matrix grains.

Evaporated seawater is a poor solvent for the majority of matrix, which is composed of seawater-precipitated carbonate grains and detrital quartz and clay silicate grains blown or washed in from surrounding areas, as seawater is saturated with respect to carbonate minerals (Chave and Suess, 1970) and simple evaporation of seawater does not increase carbonate solubility, but rather can cause precipitation to occur (McCaffrey et al., 1987).

Secondly, for the majority of the sediment grains (carbonate), their age is too young (Pleistocene to Holocene) to have had the ability to generate Ra-226 from the uranium contained within them, so that even if dissolution were occurring, there would be little radium to supply to the brine. The young age of the carbonate grains is proven by the U-234/U-238 ratio of several samples of carbonate material, which averages 1.15 (modern seawater) (Table 2). Due to the fact that production of Ra-226 is governed by the in-growth of the 76,000 y half-life nuclide Th-230 in the uranium-series decay chain, and as carbonate minerals precipitating from seawater contain little to no initial Th-230 due to its near absence in seawater (Robinson et al., 2004), insufficient time would have elapsed between time of incorporation of uranium (without Th-230) within the grain and any dissolution process, if active, presently removing the Ra-226.

Quartz and other silicate mineral grains have even lower solubility, and are less likely candidates to supply radium during dissolution, even though they may contain several parts per million of uranium and an equilibrium activity of daughter Th- 230 .

To further emphasize the shear inability of dissolution to contribute any measurable amount of radium to the sabkha solution, consider that calcite has a solubility in fresh water of about $15 \mathrm{mg} / \mathrm{l}$ and commonly contains $3 \mathrm{ppm} U$ if precipitated in a marine environment (Osmond et al., 1965; Robinson et al., 2004). Therefore about 5 $\times 10^{-8} \mathrm{~g}$ (or about $0.0006 \mu \mathrm{Bq}$ ) of uranium would be released during dissolution of calcite in 11 of water, an insignificant amount, resulting in a negligible contribution of Ra-226 even if it were in equilibrium with the uranium.

Adsorption/desorption processes are likewise thought to be of limited effect in determining the Ra-226 activity in the brine. In order for high values of Ra-226 to be found in the brine from desorption from matrix grains, a large percentage of the aquifer material would have to be composed of clay-sized material, contain a large amount of Ra226 (or Th-230 or U-234), or both. The actual composition of the aquifer material as described by Wood and coworkers states that $98 \%$ of the matrix mass is between 0.16 and $0.22 \mathrm{~mm}$ in diameter and composed of mostly carbonate and quartz grains. Typically, this type of material would have low exchange capacity, and not be expected to supply adsorbed Ra-226 to solution even as salinities increased due to evaporative concentration.

Most of the remaining 2\% of mass is either fine-grain gypsum or anhydrite (authigenic precipitates) or, depending on location, palygorskite, another authigenic material, as revealed by X-ray analysis. Only traces of additional aluminosilicate clay minerals are found. This would make it unlikely that radium brought into the sabkha adsorbed onto fine-grained material would be desorbed. Although unquantifiable, it is difficult to envision exchangeable material added during deposition of the sabkha as adding more than a trace of Ra-226 to the sabkha brine.

The final means of supplying radium from the solid matrix to brine phase is the physical process of alpha-particle recoil, whereby an atom of a decay product in a decay chain is ejected across a phase boundary by the process of alpha decay (Kigoshi, 1971). In this situation, Ra-226 could be ejected from a sabkha grain into pore-water brine as a result of the decay of its parent, Th-230. In fact, there

\footnotetext{
Notes to Table 2:

All constituents reported in $\mathrm{mg} / \mathrm{l}$, except $\mathrm{pH}$ ( $\mathrm{pH}$ units), $\mathrm{U}(\mu \mathrm{g} / \mathrm{l})$ and activity ratios (dimensionless).

Ra-228/Ra-226 activity ratios are estimated to be $\pm 10 \%$.

RP series and GWP series chemical analyses previously published in Wood et al. (2002).

a $\mathrm{U}-234 / \mathrm{U} 238$ activity ratio determined by alpha spectrometry.
} 


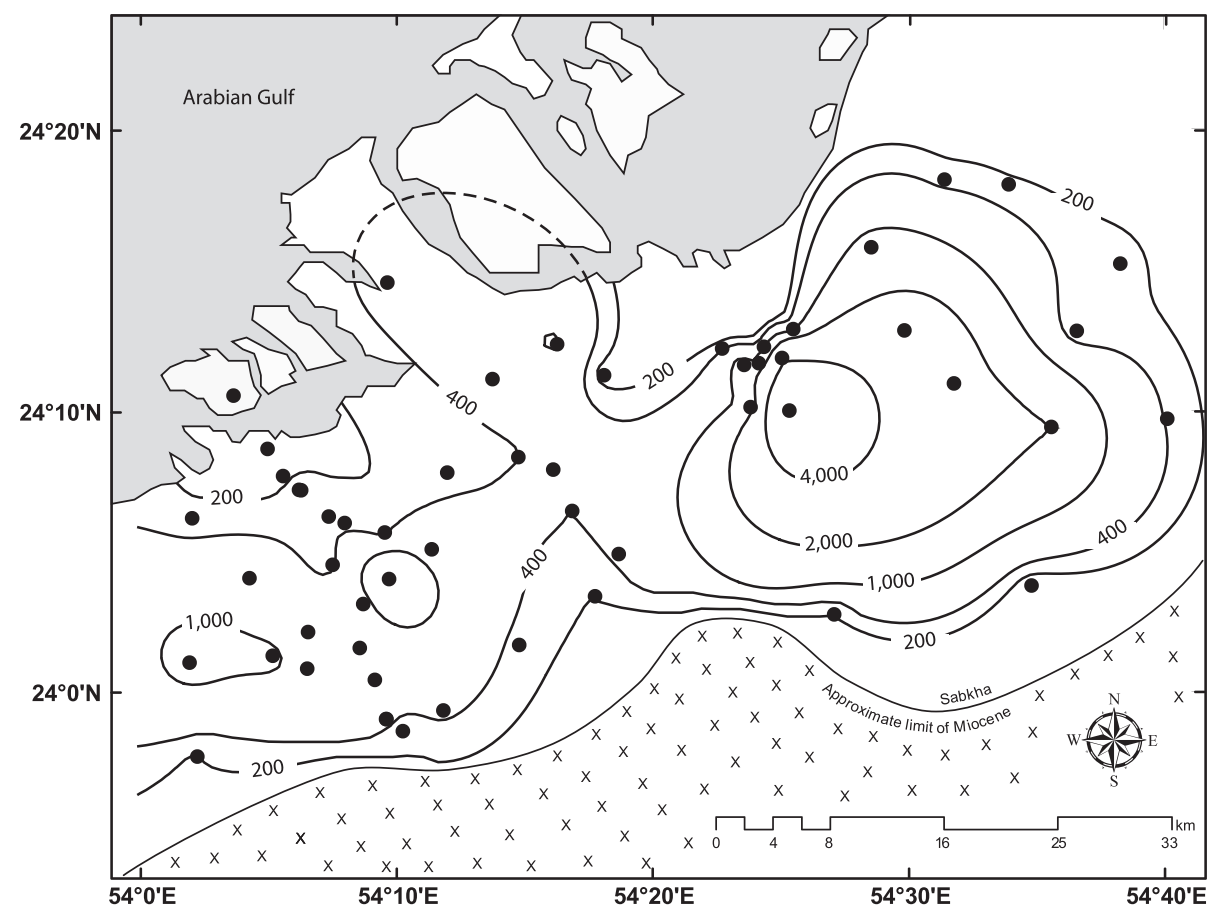

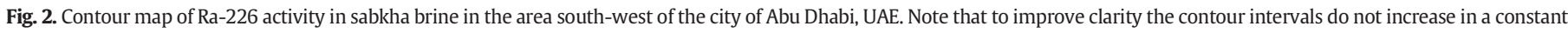
manner.

would be three opportunities for Ra-226 to ultimately enter solution as a result of alpha-particle decay, since there are three such decay modes in the uranium decay series before Ra-226 is formed (the decay of U-238 to Th-234, the decay of U-234 to Th-230, and the decay of Th-230 to Ra-226). Any of these decays could eject a nuclide that would eventually result in Ra-226 occurring in solution.

Kraemer (1981) estimated the equilibrium amount of U-234 recoiled into brine from a sand-grained matrix via alpha-particle recoil using the formula:

$$
\mathrm{U}-234_{\text {recoil }}=3 \mathrm{LU}_{\text {ppm }} \rho(1-\phi) \mathrm{C} / 4 \mathrm{r} \phi
$$

where U-234 $4_{\text {recoil }}$ is the amount of U-234 that is supplied to a saturating solution occupying the porous space of a rock, $\mathrm{L}$ is the recoil length that the decaying atom of U-234 travels as a result of alpha particle emission from the nucleus during decay of $U-238, U_{p p m}$ is the uranium concentration of the matrix grains, $\rho$ is the density of the mineral grains, $\varphi$ is the porosity of the rock, $r$ is the radius of a spherical matrix grain, and $C$ is a proportionality constant. This equation is based on the fact that U-238 will decay to Th-234 and may be transported across a grain/brine interface during this process of decay. The Th-234 then decay into U-234. A modification is needed for the present application to take into consideration that the decay of U-238 to Ra-226 involves three alpha decays (U-238 to Th-234, U-234 to Th-230, and Th-230 to Ra-226), thus giving the atom three chances to enter solution by the physical process of alpha particle recoil. We will neglect considering the chemistry of the products and the possibility of their adsorption once in solution to demonstrate the maximum supply.

Using the modified equation we have:

Ra-226 ${ }_{\text {recoil }}=3 \mathrm{NLU}_{\text {ppm }} \rho(1-\phi) \mathrm{C} / 4 \mathrm{r} \phi$

where $\mathrm{N}$ is the number of alpha decays between the decay of U-238 and the formation of Ra-226. The other symbols are as before. Using $\mathrm{N}=3, \mathrm{~L}=2 \times 10^{-8} \mathrm{~m}, \mathrm{U}_{\mathrm{ppm}}=3 \mu \mathrm{g} / \mathrm{g}, \rho=2.6 \times 10^{6} \mathrm{~g} / \mathrm{m}^{3}, \varphi=.38, \mathrm{r}$ $=8 \times 10^{-5} \mathrm{~m}$ and $\mathrm{C}=0.0125 \mathrm{~Bq} / \mu \mathrm{g} \mathrm{U}-238$, the activity present in the pore water brine at secular equilibrium will be no greater than $90 \mathrm{~Bq} / \mathrm{m}^{3}$. This, however, is a maximum value that will only occur after a period of several hundred thousand years, when the system approaches or achieves secular equilibrium. The Abu Dhabi formation, however, is only about 7000 to 8000 years old, so the Ra-226 could only have been accumulating in the pore space for this length of time. If the conditions for the above calculation were operating over 8000 years, the accumulated amount of Ra-226 would be approximately:

Ra-226 $6_{\text {recoil }}=\operatorname{Ra}-226_{\text {equil }}\left(1-\exp \left(-\lambda_{230} \mathrm{t}\right)\right)$

where Ra-226 $6_{\text {recoil }}$ is the activity of recoil accumulated Ra-226 in the brine after time t, Ra-226 equil is the activity of Ra-226 in the brine when secular equilibrium has been established, and $\lambda_{230}$ is the decay constant of Th-230, the immediate parent of Ra-226. Therefore, after 8000 years the Ra-226 activity in the sabkha brine as a result of alpha-particle recoil of Ra-226 would be about $6.3 \mathrm{~Bq} /$ $\mathrm{m}^{3}$. Even this is a maximum value, since many of the grains making up the matrix are Pleistocene carbonate grains which initially inherit little to no Th-230 during formation, and thus are incapable of supplying Ra-226 in the amount calculated in Eq. (3).

This calculation, while approximate, is intended to show the generally low transfer efficiency of alpha-particle recoiled nuclides from sandsized particles that make up the vast majority of sabkha material. It is also not likely that the sabkha matrix contains particles with significantly higher uranium concentrations than we have assumed, in that other than marine carbonates the only other sources for sediment in the region are basic to ultrabasic rocks that occur in, for example, the Oman Mountains to the east. This type of rock typically contains less uranium than marine limestones (Larsen and Gottfried, 1960). Based on the above discussion of chemical and physical process that may supply Ra-226 to brine pore water we conclude that a significant amount of Ra-226 is unlikely to accumulate as a result of their operation. A final question to be resolved is to what extent does the evaporation process itself increase in activity of Ra-226 that may be supplied to the brine by these means? 
Typically, if seawater or ascending brine containing radium were continuously supplying the sabkha, the water would evaporate, concentrating the solutes, including radium, in the remaining brine, and the evaporated volume of water would be replaced by new inflowing brine. This is obviously because there is a flow of solutes into the system without subsequent flow out. However, in the case where a component is being supplied by a process independent of what is being brought in by the external source, this concentration mechanism does not apply. Thus, the activity of Ra-226 in solution from the matrix sources would be independent of any solvent evaporation taking place as long as the pore space remains saturated with inflowing brine. To a large degree, therefore, any radium being supplied by processes acting upon the sediment matrix will not be concentrated in the brine as a result of evaporation.

C. Brine

All of the previous discussion has been to illustrate that seawater and matrix material of the sabkha are poor suppliers of radium to the brine. However, based on the data presented in Table 1, activities of Ra-226 are commonly high, and in fact many greatly exceed the estimated supply from matrix material, lending support to the proposal that some other mechanism is responsible for these values.

According to the model of Sanford and Wood (2001), ascending brine enters the Abu Dhabi formation vertically and from inflow from the proximal edge (the contact with the Miocene formations, Fig. 2), where solutes (including radium) then undergo a concentration process as a result of evaporation. To date, according to their analysis, about a seven-fold increase in conservative solutes in the brine should have occurred during the time the sabkha has been developing (about $8000 \mathrm{y}$ ), a number that is supported by the approximate seven-fold increase they found in the most conservative element, $\mathrm{Mg}$, in the sabkha brine as compared to the average geologic brine composition (Wood et al., 2002).

Ra-226, like many other non-conservative components, does not show activity increases as high as the more conservative elements like $\mathrm{Cl}$ and $\mathrm{Mg}$ as compared to the ascending brine in most cases, but does show considerably higher activity than could be accounted for by simple concentration of sea water or likely supply from matrix grains by dissolution, adsorption/desorption or alpha recoil effects. Further, the distribution of the Ra-226 under the sabkha is suggestive of the source of supply being from ascending brines as well. Fig. 2 shows the distribution of Ra-226 in the region just to the south of the city of Abu Dhabi. It is seen that the highest values of Ra-226 occupy the central portion of the sabkha, with activities decreasing generally toward the open Gulf, consistent with only the distal margin brine being formed from evaporation of seawater whose Ra-226 activity is low.

Vertical variability in radium activity is also shown by the data from the research piezometer nests. The two piezometer nests closest to the Arab Gulf (RP 2 and RP 3) show low Ra-226 activities to a depth of $4.5 \mathrm{~m}$, while the piezometer nests within the main part of the sabkha (RP1, RP5 and RP6) produce brine considerably enriched in Ra-226. Piezometer nests RP2 and RP3 represent the minor area of the sabkha where seawater is important as a contributor of brine in general for this area.

The central area of the sabkha represents an area of generally high but variable activity of Ra-226, from about 300 to over $4000 \mathrm{~Bq} / \mathrm{m}^{3}$. The large variation in Ra-226 activity within the main body of the sabkha could be due to two factors. First, the flux of up-flow of the geologic brine is likely highly variable regionally, with fractures or areas of variable hydraulic conductivity controlling flow into the aquifer. Second, the Ra-226 activity in the up-flowing brine (as represented by the GWP wells) may not be uniform over a large area. The fact that the activity at Abu $024\left(7050 \mathrm{~Bq} / \mathrm{m}^{3}\right)$ is higher than any of the deep wells which are likely supplying the sabkha, except for G1 $\left(7688 \mathrm{~Bq} / \mathrm{m}^{3}\right)$ to the extreme west of the study area, suggests that there is considerable variation of Ra-226 activity in the geologic brine.

\section{The model}

To determine whether the radium activities found in the sabkha brines are within the range expected for supply from geologic brine, the model of Sanford and Wood (2001) was applied for calculating the expected concentrations of solutes in the sabkha brines based on hydrologic parameters develop by them. The model was modified to correct for radioactive decay of Ra-226 that would occur during the accumulation period in the sabkha aquifer. The modified equation is thus:

$A_{p w}=\left(A_{i} Q / b \lambda\right)(1-\exp (-\lambda t))$

where $A_{p w}$ is the Ra-226 activity of the pore water $\left(B q / m^{3}\right), A_{i}$ is the Ra-226 activity in the ascending brine $\left(\mathrm{Bq} / \mathrm{m}^{3}\right), \mathrm{Q}$ is the flux of water through the base of the aquifer from below $\left(\mathrm{m}^{3} / \mathrm{m}^{2} / \mathrm{y}\right)$, $\mathrm{b}$ is the aquifer thickness ( $\mathrm{m}), \lambda$ is the decay constant for Ra-226 (1/y), and $\mathrm{t}$ is the time $(y)$ that the sabkha aquifer has been accumulating the ascending brine. Using values for $A_{i}$ of $3416 \mathrm{~Bq} / \mathrm{m}^{3}$ (the mean of the GWP samples, Table 1), Q of $0.0025 \mathrm{~m}^{3} / \mathrm{m}^{2} / \mathrm{y}$, b of $10 \mathrm{~m}, \lambda$ of $0.000433 \mathrm{y}^{-1}$, and a solute accumulation time of $8000 \mathrm{y}$ (all values from Sanford and Wood, 2001), the model predicts that the present day Ra-226 activity in the sabkha aquifer brine would be $710 \mathrm{~Bq} / \mathrm{m}^{3}$, taking into account both evaporation concentration effects and radioactive decay. This value is within the range of measured values found for the sabkha samples, is well above what could likely be expected from seawater and matrix supply, and is therefore consistent with the ascending brine model, considering the many field variables that are not well constrained, as discussed below.

Reasons for variation in radium activity found in the sabkha aquifer brine, in addition to those already mentioned, could be the result, at least in part, of differences in brine upwelling rate over geographic area due to variation in hydrologic properties of the rock through which the ascending brine must flow, and a slow horizontal mixing along the axis of the sabkha aquifer.

Additionally, as the ascending brine is transported to the Abu Dhabi formation from deeper it must transit through up to $100 \mathrm{~m}$ of intervening formation between these deep aquifers and the base of the Abu Dhabi formation. The transit time through these formations to the base of the Abu Dhabi formation could allow for significant decay of the Ra-226 depending upon the length of time it takes the solutions to cover these distances, assuming no additional sources of radium to (or removal from) the solution from the passed-through formations themselves.

Another cause of radium variation in sabkha pore-water solution after delivery is co-precipitation with barium sulfate (barite), a process that is well known to remove radium from solution (Doerner and Hoskins, 1925; Zhu, 2004). The fact that sabkha samples contain appreciable activities of radium is a strong indication, however, that barite precipitation does not occur extensively from the sabkha brine, since even a small degree of barite precipitation would likely quantitatively remove a majority of radium from solution. However, there are processes and conditions that can occur in aquifers that could allow for the presence of radium in barite-saturated water, under certain situations (such as if the radium entered the pore space after barite precipitation).

\section{Summary and conclusions}

Wood et al. (2002) proposed an explanation for the origin of hypersaline brine of the sabkhat of coastal Abu Dhabi that addressed shortcomings in previous seawater based models and incorporated known hydrologic facts concerning flow rates and head properties of fluids in the deeper aquifer. Although the ascending brine model (ABM) was an improvement over previous models in its compatibility with existing information, the present-day functioning of such a model could not at the time be conclusively demonstrated. Analysis of Ra-226 in sabkha 
brines has shown that contribution of deep geologic brines is the only reasonable source of the radium, and, therefore, other solutes.

The 1601 y half-life of Ra-226 and the abundance of this nuclide in the ascending deep basin brine allowed for an evaluation of the ABM model. Results of model calculations are within the range of actual measurements of radium in sabkha brines and show that the ABM can explain existing radium occurrence in modern sabkha brines, and that the processes described by the model are operating currently and/or in the recent past. We therefore conclude that the ABM is valid and currently active and responsible for the solutes found in the brines of the Abu Dhabi sabkhat. As a result we have 1) confirmed a general model for the possible origin of solute sources in coastal environments, and 2 ) resolved a classic question on the origin of solutes in the Abu Dhabi coastal sabkha that has been the subject of interest and debate in the literature for over 50 years. This knowledge could be important in managing the resources of low lying sabkha environments worldwide in response to future human efforts of development and mitigating effects of climate-induced sea level rise. It may also necessitate a re-evaluation of the interpretation of sabkha sediments in the geologic record.

\section{Acknowledgments}

Our thanks go to David Clark, Chief of Mission, U.S. Geological Survey, and the National Drilling Company (Abu Dhabi) for access to data and providing field support while in Abu Dhabi. Any use of trade, product, or firm names is for descriptive purposes only and does not imply endorsement by the U.S. Government.

\section{References}

Butler, G.P., 1969. Modern evaporite deposition and geochemistry of coexisting brines, the sabkha, Trucial Coast, Arabian Gulf. J. Sediment. Petrol. 39, 70-81.

Charette, M., Breier, C., Henderson, P., Pike, S., Rypina, I., Jayne, S., Buesseler, K., 2013. Radium-based estimates of cesium isotope transport and total direct ocean discharges from the Fukushima nuclear power plant accident. Biogeosciences 10, 2159-2167.

Chave, K., Suess, E., 1970. Calcium carbonate saturation in seawater: effects of dissolved organic matter. Limnol. Oceanogr. 15 (4), 633-637.

Doerner, H.A., Hoskins, W.M., 1925. Co-precipitation of radium and barium sulfates. J. Am. Chem. Soc. 47 (3), 662-675. http://dx.doi.org/10.1021/ja01680a010.

EPA, 1994. Methods for determination of metals in environmental samples-Supplement 1, U.S. Environmental Protection Agency,. EPA-600/R-94-111.

Evans, G., 1995. The Arabian Gulf: A modern carbonate-evaporite factory; a review, in Cuadernos de Geologica Iberica: Madrid,. Servicio de Publicaciones, Universidad Complutense 19, 61-95.

Fadlelmawla, A., Al-Senafy, M., Charette, M.A., 2013. Anthropogenic and natural controls on coastal groundwater exchange in an arid region (Kuwait) (written communication).

Hsü, K.J., Schneider, J., 1973. Progress Report on Dolomitization - Hydrology of Abu Dhabi Sabkhas, Arabian Gulf. In: Purser, B.H. (Ed.), The Persian Gulf. Springer-Verlag, New York (471 pp.).

Hsü, K.J., Siegenthaler, C., 1969. Preliminary experiments on hydrodynamic movement induced by evaporation and their bearing on the dolomite problem. Sedimentology $12,11-25$.

Kigoshi, K., 1971. Alpha-recoil thorium ${ }^{234} \mathrm{Th}$ : dissolution into water and the uranium234/uranium 238 disequilibrium in nature. Science 173, 47-48.

Kinsman, D.J.J., 1969. Modes of formation, sedimentary associations, and diagnostic features of shallow-water and supratidal evaporates. Am. Assoc. Pet. Geol. Bull. 53, 830-840.
Kraemer, T., $1981 .{ }^{234} \mathrm{U}$ and ${ }^{238} \mathrm{U}$ concentration in brine from geopressured aquifers of the northern Gulf of Mexico basin. Earth Planet. Sci. Lett. 56, 210-216.

Kraemer, T.F., Reid, D.F., 1984. The occurrence and behavior of radium in saline formation water of the U.S. Gulf coast region. Chem. Geol. 46 (2), 153-174.

Kraemer, T., Doughten, M., Bullen, T., 2002. Use of ICP/MS with ultrasonic nebulizer for routine determination of uranium activity ratios in natural water. Environ. Sci. Technol. 36, 4899-4904.

Larsen, E.S., Gottfried, D., 1960. Uranium and thorium in selected suites of igneous rocks. Am. J. Sci. 258-A, 151-169.

Liu, G., Men, W., Ji, L., 2010. Calculation of vertical mixing rate based on radium isotope distributions in the Yellow Sea and East China Sea. Chin. J. Geophys. 53, 862-871.

McCaffrey, M.A., Lazar, B., Holland, H.D., 1987. The evaporation path of seawater and the coprecipitation of $\mathrm{Br}$ and $\mathrm{K}$ with halite. J. Sed. Petrol. 57 (5), 928-937.

McKenzie, J.A., Hsü, K.J., Schneider, J.F., 1980. Movement of subsurface waters under the sabkha, Abu Dhabi, UAE, and its relation to evaporative dolomite genesis. SEPM Special Publication No. 28, pp. 11-30.

Moore, W.S., 1976. Sampling 226Ra in the deep ocean. Deep-Sea Res. 23, 647-651.

Moore, W.S., 1981. Radium isotopes in the Chesapeake Bay. Estuar. Coast. Shelf Sci. 12, 713-723.

Moore, W., Key, R., Sarmeinto, J., 1985. Technique for precise mapping of 226Ra and 228Ra in the ocean. J. Geophys. Res. 90, 6983-6994.

Müller, D.W., McKenzie, J.A., Mueller, P.A., 1990. Abu Dhabi sabkha, Persian Gulf, revisited: application of strontium isotopes to test an early dolomitization model. Geology 18 , 618-621.

Ohta, T., Mahara, Y., Kubota, T., Sato, J., Gamo, T., 2011. Concentrations and activity ratios of 228Ra and 226Ra in surface seawater along the Pacific Coast of Japan. Proc. Radiochim. Acta 1, 183-188.

Okubo, T., Furuyama, K., Sakanoue, M., 1979. Distribution of 228Ra in surface sea water of the East Indian Ocean. Geochem. J. 13, 201-208.

Osmond, J.K., Carpenter, J.R., Windom, H.L., 1965. Th-230/U-234 age of the Pleistocene corals and oolites of Florida. J. Geophys. Res. 70 (8), 1843-1847.

Patterson, R.J., Kinsman, D.J.J., 1977. Marine and continental groundwater sources in a Persian Gulf coastal sabkha. Stud. Geol. 4, 381-397.

Patterson, R.J., Kinsman, D.J.J., 1981. Hydrologic framework of a sabkha along Arabian Gulf. Am. Assoc. Pet. Geol. Bull. 65, 1457-1475.

Patterson, R.J., Kinsman, D.J.J., 1982. Formation of diagenetic dolomite in coastal sabkha along Arabian (Persian) Gulf. Am. Assoc. Pet. Geol. Bull. 66, 28-43.

Peebles, R.G., 1999. Stable Isotope Analyses and Dating of the Miocene of the Emirate of Abu Dhabi, United Arab Emirates. In: Whybrow, P.J., Hill, A. (Eds.), Fossil Vertebrates of Arabia. Yale University Press, New London, pp. 88-105.

Robinson, L., Belshaw, N.S., Henderson, G.M., 2004. U and Th concentrations and isotope ratios in modern carbonates and waters from the Bahamas. Geochim. Cosmochim. Acta 68 (8), 1777-1789. http://dx.doi.org/10.1016/jgca.2003.10.005.

Sanford, W.E., Wood, W.W., 2001. Hydrology of the coastal sabkhas of Abu Dhabi, United Arab Emirates. Hydrogeol. J. 9 (4), 358-366.

Su, N., Du, J., Ji, T., Zhang, J., 2010. 226Ra and 228Ra tracer study on nutrient transport in east coastal waters of Hainan Island, China. Water Sci. Eng. 4 (2), 157-169.

Van Dam, R., Simmons, C., Hyndman, D., Wood, W., 2009. Natural free convection in porous media: first field documentation in groundwater. Geophys. Res. Lett. 36, L11403. http://dx.doi.org/10.1029/2008GL036906.

Vengosh, A., Hirschfeld, D., Vinson, D.S., Dwyer, G.S., Raanan, H., Rimawi, O., Al-Zoubi, A., Akkawi, E., Marie, A., Haquin, G., Zaarur, S., Ganor, J., 2009. High naturally occurring radioactivity in fossil groundwater in the Middle East. Environ. Sci. Technol. 43 (6), 1769-1775. http://dx.doi.org/10.1021/es802969r.

Wood, W.W., Sanford, W.E., 2002. Hydrogeology and Solute Chemistry of the CoastalSabkha Aquifer in the Emirate of Abu Dhabi. In: Barth, Hans-Joerg, Boer, Benno (Eds.), Sabkha Ecosystem, v. 1 - The Sabkhas of the Arabian Peninsula and Adjacent Countries, 173-185. Kluwer Academic Publishers, Dordrecht (354 pp.).

Wood, W.W., Sanford, W.E., 2007. Atmospheric bromine flux from the coastal Abu Dhabi Sabkhat: a ground-water mass-balance investigation. Geophys. Res. Lett. 34, 14. http://dx.doi.org/10.1029/2007GL029922.

Wood, W.W., Sanford, W.E., Al Habschi, A.R.S., 2002. The source of solutes in the coastal Sabkha of Abu Dhabi. Bull. Geol. Soc. Am. 114 (3), 59-268.

Wood, W.W., Sanford, W.E., Frape, S., 2005. Chemical openness and potential for misinterpretation of the solute environment of coastal sabkhat. Chem. Geol. 215 (1-4), 361-372.

Zhu, C., 2004. Coprecipitation in the barite isostructural family: 1. binary mixing properties. Geochim. Cosmochim. Acta 68, 3327-3337. 